\title{
Response of horticultural crops under variable microclimatic conditions of different protected cultivation structures
}

\author{
D.T. Santosh \\ Center for Smart Agriculture, Centurion University of Technology and Management, \\ Paralakhemundi (Odisha) India (Email: santosh.dt@cutm.ac.in)
}

\begin{abstract}
Protected cultivation structures provide favorable environment for crop growth thereby achieving greater yield and high quality produce. The objective of this work was to evaluate the microclimate parameters such as temperature, relative humidity, solar radiation and light intensity underdifferent protected cultivation structures in comparison with open field condition. Four types of protected cultivation structures (polyhouse, walking tunnel,shadenet house and modified greenhouse) were considered for the study. Meteorological data of seven years (2010-2016), recorded on daily basis were used for micro climate analysis of different protected cultivation structures. FAO-56 Penman Monteith approach was used to estimate the reference crop evapotranspiration under different kind of protected cultivation structures. Study shows that walking tunnel, polyhouse and modified greenhouse structures offers a solar energy saver and enhances temperature inside the structures. The total water requirement of drip irrigated crops in protected cultivation structure is reduced by about $25 \%$ to $35 \%$ under different protected cultivation structures in comparison to open field cultivation. This paper also presents the difference incrop yield grown under protected cultivation structures and open field condition.
\end{abstract}

Key Words : Temperature, Relative humidity, Polyhouse, Shadenethouse, Walking tunnels

View Point Article : Santosh, D.T. (2021). Response of horticultural crops under variable microclimatic conditions of different protected cultivation structures . Internat. J. agric. Sci., 17 (2) : 515-521, DOI:10.15740/HAS/IJAS/17.2/515-521. Copyright@ 2021: Hind AgriHorticultural Society.

Article History : Received : 18.03.2021; Revised : 04.03.2021; Accepted : 18.03.2021 